\title{
Implementation of Electronic Medical Records for Service Delivery in Selected State Hospitals in Southwest Nigeria
}

\author{
Stephen Adekunle Ajayi ${ }^{1}$, Peter Wamae ${ }^{2}$, Daniel Wambiri Muthee ${ }^{3}$ \\ ${ }^{1,2,3}$ Department of Library and Information Science, Kenyatta University, Kenya
}

\begin{abstract}
Electronic Medical Records (EMR) is an important communications channel relating to patient health conditions. Unfortunately, many hospitals in Africa, including Nigeria, have not implemented EMR. The few Hospitals that have some level of EMR continues are still struggling with the use of paper and hybrid medical records, which has led to inadequate medical follow-up, medical error, and long waiting time for patients. A sample size of three hundred and ninety-seven (397) was determined using krejcie and morgan models, comprising of strategic managers, and the operational staff drawn from a population of 2889 in the selected hospitals. At the hospital level, purposive sampling was applied in picking strategic managers, while stratified random sampling was method was used to select operational health workers. Questionnaires were used for data collection. The study adopted a descriptive statistical analysis method to describe the existing medical records systems. The finding indicated that the systems in the hospitals are mainly paper-based. The hospitals are also using hybrid system with a few treatment areas having fully electronic medical records systems. In the area where EMR has been implemented, the finding indicates poor penetration of the EMR system, limited modules, staff readiness and poor performance in the treatment area, among others. The study concluded that hospitals that have implemented, EMR is not serving the classical purpose of medical record of supporting treatment and follow up. The study recommended that the selected hospitals should ensure there is the availability of fund, staff training, and technical infrastructures like electronic record managers, ICT support staff, and computer compatible medical devices, among others.
\end{abstract}

Key Words: Electronic Medical Records, Service Delivery, State Hospitals

DOI 10.35942/ ijcab.v5i2.174

Cite this Article:

Ajayi, S., Wamae, P., \& Muthee, D. (2021). Implementation of Electronic Medical Records for Service Delivery in Selected State Hospitals in Southwest Nigeria. International Journal of Current Aspects, 5(2), 75-94. https://doi.org/10.35942/ijcab.v5i2.174

\section{Introduction}

Medical records form an essential part in management of patients healthcare. Bali, et al (2011), in their article on "Management of Medical Records: fact and figures", argued that Medical records are detailed documents about the patient's health history, clinical investigations, laboratory result generation, drug prescriptions, patient's progress, among others. Medical records are generated in all healthcare units, and it covers an array of documents like doctors notes, discharge summaries, referral letters to and from other hospital and health units. Laboratory reports audiovisual records clinical research form, death and birth certificate, nurses note, and medication chart. A detailed medical record serves the interest of the medical practitioner and his patients. They are maintained for treatment and follow-up, medical audit and report generation for decision-making, legal purposes and investigating patient health profiles. Regardless of form a good medical records should enhance patients' treatment and follow-up and improve communication between different healthcare units and professionals. 
Low medical records management system has led to many setbacks experienced in the health sector. The World Health Organization (WHO) issued a report in 2006, titled Medical Records Manual (MRM) for developing nations. The guidelines stated that locating patient medical records is vital, as it gives useful information on prevention and management of patients. The guideline avers that most African countries are still using paper-based medical record system. The study did not identify challenges associated with a paper-based medical records system.

In a study conducted by Flores (2015) on "Paper Based Medical Records", posit that Paper record is documentation created by doctors and other healthcare givers during patients visit to take control and monitoring treatment and follow up of the patient. Management of patients records is governed depending on countries medical laws and regulations. According to Ondieki (2017) healthcare providers in public health facilities are still using paper-based records to collect patient data a study conducted in a Teaching and Referral Hospital (TRH) on the Effects of Health Records Management on Service Delivery. It was found that as a result of the hospital's inadequacy handling of patients' records, it was difficult to provide timely and reliable health care service to patients. Other challenges experienced included medical errors and prescription errors among others. Alegbeleye (2009), in his paper at the Nigerian Library Association's (NLA) 47th National Conference on digital information preservation, explained that hospitals are the highest creation of records in most developing countries.

Ijeoma (n.d.) in his research on the challenges facing management of medical records in public hospitals points out that hospitals are faced with challenges of management of medical records, such as "lack of Medical Records Management standards, preservation, and conservation policies, inadequate storage facility, and poor filing system; inadequate funding, inadequate ICT facilities, literacy skill, and environmental factors". These challenges calls for a new approach to healthcare service delivery that will cater for the 21 st-century health delivery system. The shift from paper-based storage and retrieval of medical data to digital systems like hybrids medical records system and electronic medical system has open the door to new ways of providing care and a greater knowledge of the health-care system's operations and outcomes. According to Techtarget (2010) a hybrid health record (HHR) is a collection of a person's medical records that are kept in numerous formats and stored in multiple locations. In today's world, the majority of health records in the United States are hybrid. Because the records administrator must utilize both human and electronic methods to identify which data elements, electronic documents, photographs, audio, and video files should become part of the legal electronic health record, hybrid health records pose a problem. They must also identify the location of the information in the record so that it may be promptly accessible.

A hybrid system is an appealing option for healthcare providers that are not ready to make the full transition to electronic medical records (EMRs). Many times, institutions have massive amounts of paper documents that are too difficult to convert to digital records. Hybrid records, on the other hand, are more expensive for healthcare providers since they require more people and time to manage. According to Kang'a, Puttkammer, Wanyee, Kimanga, Madrano, and Muthee (2016) in their article on national standards-based evaluation of the functionality of electronic medical record systems used in Kenyan found out that Low-income countries in developing countries such as south Africa, Ethopia, Kenya, Ghana and Nigeria are now following this trend of using hybrid medical records as developed countries by replacing paperbased systems with digital systems. EMRs are computer-based health information systems in the health facilities for documenting the medical history, treatment offered, and follow up statement collected by the caregivers in a hospital. Most EMR programs deal allows capture of demographics and clinical health history; support and preparation of clinical decision; 
prescriptions by doctors; reporting of information; safety and confidentiality of patient information and Electronic data exchange, among others.

In Nigeria, government teaching hospitals have been making an effort to deploy technology for better service delivery. Ojo and Popoola (2015) examined the efforts being made by five teaching hospitals (University College Hospital, Ibadan; the University of Abuja Teaching Hospital, Abuja; University of Ilorin Teaching Hospital, Ilorin; and Lagos State University Teaching Hospital and Ikeja) into the introduction of EMR and the difficulties they encountered. Although, the finding shows that some of the hospitals that have implemented EMR, the application is only covering for patient's registration and patients billings. The result showed that most of the hospitals did not carry out full readiness assessment before implementation, which has led to poor perception and inability of the EMR to achieve its intended purpose. The study conclusion was that EMRs were not serving the clinical purpose of supporting treatment. Meriboleet, et al (2014) noted in a study to review the policy that Nigeria's health information system is not delivering healthcare progress at the rate predicted. Olaronke et al. (2013) found that only about four percent of general practising practitioners in Nigeria use IT applications for clinical purposes cited in the article on Interoperability in Nigeria Healthcare System. Ayangbekun and Oke (2014), in their study on comparative analysis of existing health information systems for the development of Nigerian Health Sector, found out that healthcare providers in Nigeria lack access to best-required technology skills and facilities to provide good services as a result of the challenges faced by the implementation of National Health Management Information System (NHMIS) among which are: inadequate funding, insufficient staffing, Shortage of infrastructure, poor coordination of data and workflow, epilepsy power supply and Huge backlog of unprocessed data, training, IT literacy among others.

\section{Literature Review}

Baldwin (2019), in his study on electronic medical records advise that a standard electronic medical records application to include "hospital Patient history; clinical charting; lab and x-ray orders results; patient referrals reports; fee schedule; interoperability of systems among other features". Dhar (2018), notes that EMRs have improves efficiency in maintaining patient information compared to paper-based patient records. Caregivers who use EMR can reduce medical errors and spend less time searching through paper files for information. In ensuring EMR readiness, development of a plan and assessment of resources within hospital facilities is a necessary step in determining the success and failure of implementing EMR. Ghazisaeidi, Ahmadi, Sadoughi, and Safdari (2014), in their study on readiness, posit that EMR Readiness gives a true picture of the existing hospital conditions and it revolves around investigating and assessing various aspects of a hospital to identify potential problems and to address them before implementation occurs. From the global perspective, evidence show that readiness for EMR implementation in some hospitals has enhanced performance among healthcare workers, especially in the area of report generation, enhanced treatment and follow up. Similar findings have also been reported in a study conducted by Lorenzi, Kouroubali, Detmer, Bloomrosen (2009). According to the study, EMR performance is based on readiness metrics as well as technology, literacy, leadership and change management in the small ambulatory institutions in the US on the effective implementation of electronic medical records in small ambulatory institutions. The study lay more emphasis on the role of management in getting ready for EMR implementation without considering ICT infrastructure and resources as a major indicator for implementation.

In his research on the successful implementation of electronic medical records in the United States America (USA), Kaufman (2009) found that readiness assessment offers proper 
budgeting, planning, and decision making based on the existing reality and constraint of the hospital. In a study by Health Information Technology for Economic and Clinical Health (HITECH) (2017) on overcoming challenges of implementing EMR it was found out that failure was recorded in EMR implementation as a result of a lack of ICT infrastructure and resources assessment. The study also showed that Staff members struggled to use the new technology and as a result, spent more time on delivering services. Based on this study, the implementation processes seems to portray poor perception on the part of the staff of the hospital, leading to the unacceptability of the EMR among health worker. Khoja, et al (2007) in a study on electronic medical readiness assessment tools in health institutions in developing countries, found out that "EMR readiness assessment enables organisations and governments to avoid patients issues such as time, waste of financial resources, disappointments among EMR, users lack of support intreatment and follow up, legal and research decision making. Adequate preparation empowers health facility in the process of technological change, other change issues aimed at enhancing EMR acceptance.

In Africa, studies have shown that there is a need for gradual change in the EMR. Research findings on implementation indicates that, some of the functions of EMR are gradually penetrating the African healthcare system to make better healthcare delivery. Bello, Faruk, Oloyode and Popoola, (2016), in their study on driving electronic health record system implementation, argued that, the level of readiness for the implementation of electronic medical records in most developing nations has been low. They noted that, "the use of electronic record management is relatively new in countries. In countries like Ethiopia, South Africa, Kenya, Tanzania, Uganda, and Ghana are showing some level of readiness and some of these countries have implemented some of the functions of the electronic medical record in most of their major hospitals, has been noted level electronic medical record has been noted, but have not been able to achieve much progress as a result of some challenges. It was reported that these countries have continued to face challenges like poor political will, poor socioeconomic stability, lack of technological infrastructures factors, inadequate skills to handle EMR technologies, weak organisation structure, as well as diverse stakeholders, and bureaucratic constraints.

Biruk, Yilma, Andualem, and Tilahun (2014), in their study on health worker readiness to implement an EMR system in Ethiopia, reported low use of EMR as a result failure to include the operational staff in the hospital readiness plan. The low acceptance was also associated with failure to assess perception of healthcare staff before implementation EMR. The finding did not indicate the type of readiness that was not conducted, which leads to failure. Yogeswaran and Wright (2010), in their study on EMR implementation in South Africa, argued that successful technology readiness in terms of ICT infrastructure and resources was conducted on EMR implementation, and the hospitals were able to achieve remarkable improvement in the treatment and follow up of their patients. Readiness is a determining factor in whether or not an electronic medical record is implemented successfully in a hospital. Acquah-Swanzy (2015) conducted a study on evaluating the electronic medical records system in Ghana and posited that readiness allows any health centre to identify hindrances associated with the implementation of the EMR system. Kaufman (2009) argued that Failure is inevitable for any health facility that fails to conduct a readiness test before implementing EMR in the healthcare centre. Adjorlolo and Ellingsen (2013), in their study on Readiness Assessment for Implementation of Electronic Medical Record at the University of Ghana hospital, reported high failure rate of EMR implementation in Africa as a result of a failure in availability of ICT infrastructure, staff training and management readiness assessment. The above findings did not 
identify the area of readiness that was not assessed and the area of success. Ojo and Popoola, (2015), in their study on electronic health information management system in Nigeria, found out that political, socioeconomic, technological, bureaucratic constraints, organisation structure, inadequate ICT skills and lack of readiness on the part health workers, strategic health managers and government has hindered the implementation of EMR.

Esomu,(2017), in his their articles on 21st century medical records in Nigeria, avers that hospital in tertiary institutions uses paper-based medical records which are error-prone due to poor communication, record mutilations, missing patient information pages and inadequate storage capacity among healthcare providers. The findings indicate that Nigerian health care practitioners are prepared to change to EMR, considering the lapses in their paper systems, if prior to implementation, they have taken into consideration the problems of fearing loss of employment, administrative support to IT and related practices, lack of confidence and other legal issues, workflow management, inappropriate computer literacy capabilities, privacy, confidentiality. Therefore, despite being one of the Millennium Development Goals (MDG) and an International Organization for Standardization (ISO/TR 20514) standard, IT tools to seamlessly exchange health data appear to be inaccessible within the context of Nigeria health system. Ayanlade (2018) in a study in Nigeria on the electronic medical record system as a central ICT tool for quality healthcare services reported. The result showed a positive perception of EMR use among practitioners with the belief that EMR will bring efficiency and effectiveness to healthcare services in southwestern Nigeria. The findings also showed heavy use of paper-based records in southwestern teaching hospitals which has pose a lot of challenges to various services provided by the hospitals.

In a report to analyse doctors' attitudes and willingness to use electronic medical records at the Lagos University Teaching Hospital (LASUTH) in southwest Nigeria, Onigbogi, Poluyi, Poluyi, and Onigbogi (2018) found that there is low ICT skills acquisition among doctors in the hospital. The finding also showed that the hospital has implemented some level of EMR to improve record performance, reduce patients waiting time and improve service delivery, but the implementation has not reduced the long waiting time in the hospital. It was not known if the hospital conducted readiness before implementation. Abodunrin and Akande (2009), in their publication on Knowledge and Perception of e-Health and Telemedicine among Health Professionals in LadokeAkintola University Teaching Hospital (LAUTECH) Oshogbo southwest Nigeria, found out that majority of the health workers had a good perception of how EMR can enhance their services. The finding also showed a low percentage of staff training towards the use of electronic medical records in the hospital. This was attributed to challenges like inadequate ICT facilities, poor internet connection, poor power supply, computer literacy, insufficient funding, among others. Edward, Iwaola, Adumaza, and Fayose (2020) in their article entitled Factors Affecting Implementation of Computer-Based Clinical Documentation Among Nurses in Selected Hospitals, Ondo State, found that the hospital uses EMR for registration patients and despite the challenges identified as hindering to the full implementation of EMR in the hospital, there is a good perception that if fully implemented it will improving the performance of health care workers in the hospital. The finding shows that the hospital is faced with challenges related to ICT infrastructure and training of staff for the adoption of fully implementation EMR. It is against this background that this study intends to study the implementation of EMR for service delivery in selected state hospitals in Southwest Nigeria.

\section{Research Methods}

Being a study on EMR implementation, descriptive design was selected to show the current EMR situation in the selected state universities teaching hospitals in southwest Nigeria. The 
study was conducted in four selected state university teaching hospitals in Nigeria namely, Osun state, Lagos state, Ondo state, and Ekiti state, respectively. This study population included strategic hospital managers such as medical directors and department heads and operational health workers such as doctors, nurses, pharmacists, health information managers, physiotherapists, radiologists, medical laboratory personnel, maternity and family care personnel, planning and research and finance personnel. The operational staff were of importance to this study because as users of EMR they hold information on the whether it is easy to use and benefiting them in service delivery, how the management has prepared them for EMR implementation. Health workers are expected to benefits more in the implementation. The strategic managers as the decision makers and strategic driver of the institution they are expected to spearhead the implementation process of EMR, through financing and planning, and to provide information on the readiness level of the hospital.

The sample size determination was based on Krejcie and Morgan (1970) Sample Size Determination Table for $\pm 5 \%$ precision level and $95 \%$ confidence level. It stated that when the population is 2,889 at $\pm 5 \%$ precision, 397 should be the sample at a $95 \%$ confidence level. This means each hospital sample was calculated proportionately by using a formula recommended by Krejcie and Morgan. The study used two questionnaires, one for strategic mangers and the other for operational staff. The instruments are suitable for collecting data from the group of respondents. The methods enabled the researcher to obtain more accurate information as the instrument allows face to face interaction during data collection and give room for on the field observation. Also, the instrument allows confidentiality and can be used to collect information from a large group of respondents.

The research adopted a quantitative research method. With the aim of the study to investigation of readiness and state of implementation of EMR, inorder to capture descriptive data on the existing scenario quantitative methods which allows for genralisation and capturing of numeric data was found suitable for this study.This method was found suitable, as it enable the researcher to capture quantitative parameters. The Quantitative (Questionnaire) method suitable and it enable the researcher to capture data on available ICT infrastructure and resources,and level of implementation of EMR from each department of the selected state universities teaching hospitals. The questionnaire was used because of it ability to capture large respondents. The strategic manager's readiness and implementation was measured quantitatively through the use of a questionnaire. The variable was measured using Management readiness, financial readiness, implementation plans and focus, challenges of EMR implementation, Hospital policies and law guiding EMR use, and operational readiness of EMR implementation in the hospital selected was also captured through a questionnaire. It allowed the respondents to answer questions related to the readiness and implementation of EMR for service delivery anonymously, considering their confidentiality.

\section{Data Analysis Results}

\subsection{Types of medical records system in Selected Hospitals}

According to Stausberg, med, Koch, Ingenerf, Nat and Betzler (2003), the common types of medical records in the hospitals are paper-based, hybrid and electronic system. To confirm the types of medical records the, three hundred and ninety seven (397) respondents were asked to identify the type of EMR system used in their various hospitals. Two hundred and sixty nine (269) responded, in order to determine the extent in which electronic system has penetrated the selected hospitals. The result are indicated in figure 41 below. 


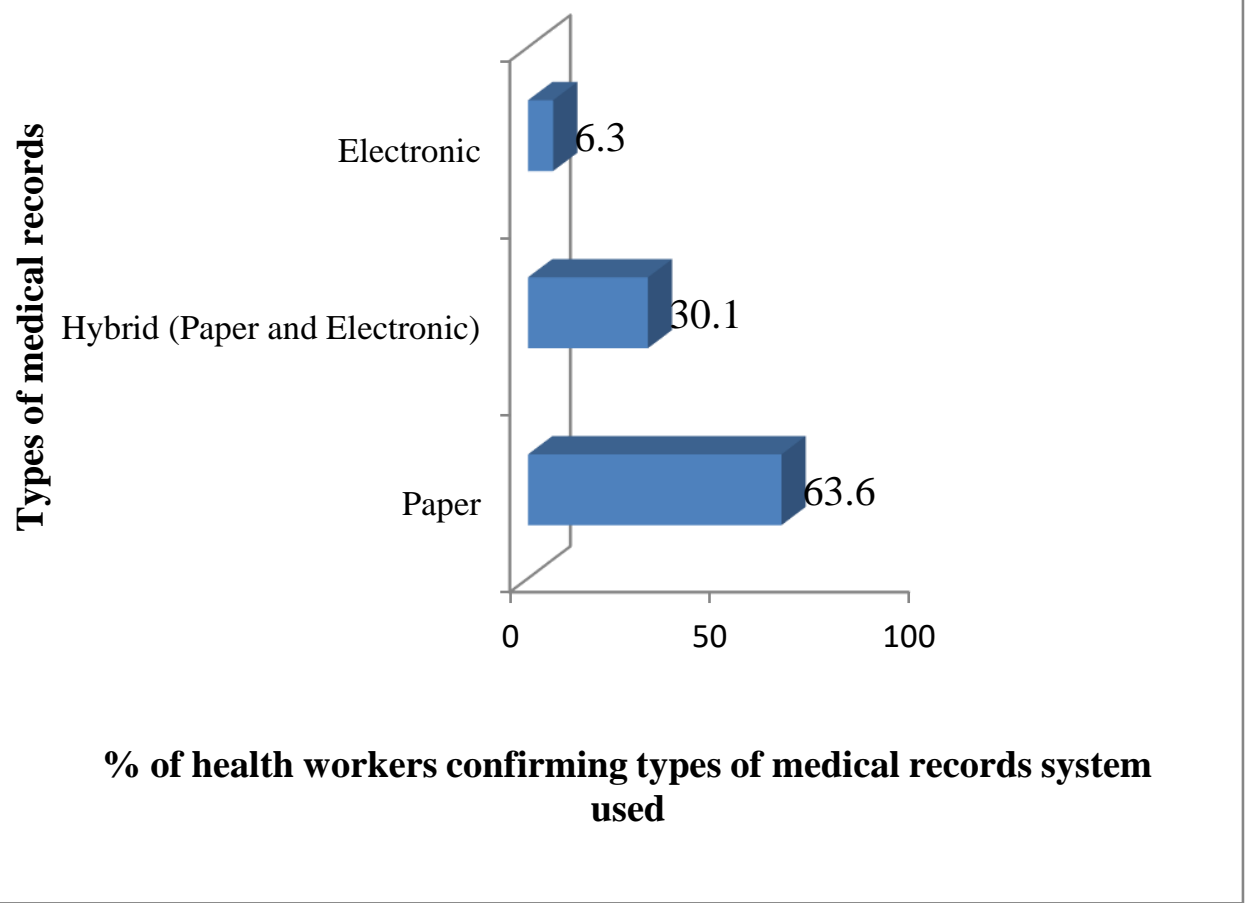

Figure 1 Types of medical records system in selected Hospitals

\section{Source: Research questionnaires 2020}

From the data provided in figure 1 it is apparent that the type of medical records currently being used in the hospitals in Southwest Nigeria was mostly paper-based records. Data show that almost three quarter (63.6\%) of the respondents confirmed there was a heavy use of paper based medical records in the hospitals under study. Slightly, above one quarter $(30.1 \%)$ medical records of the hospitals are in hybrid (paper and electronic) form. Also the above data shows that only $6.1 \%$ of the medical records in the hospitals are in full electronic form. These finding shows that majority of the medical records created in hospitals in the hospitals understudy are in paper form, although the analysis also shows little penetration of electronic medical records in all the hospitals. this means that the hospitals under study are likely to face the problem associated with paper based records such as poor communication, record mutilations, missing patient information pages and inadequate storage capacity among others which can be resolve using EMRas reported by Esomu (2017), Abdulkadir, Yunusa, Tabari, Anas, Ojo, Akinlade, Suleman and Uyobong, (2011).

\subsection{Patient Data Capturing Methods in selected hospitals}

Data capture method is a key determinant of system efficiency in terms of time taken in achieving workflow and services delivery. (Sarkies, Bowles, Skinner, Mitchell, Haas, Ho, Salter, May, Markham, O'Brien, Plumb, Haines 2005). To determine the types of methods being used for of data capture such as on paper first and entered later by data personnel to the computer, Manually captured only on paper, captured electronically at the point of service and data captured on paper and some electronic, the three hundred and ninety seven (397) health workers respondents were asked to state the methods being used The result from the 269 respondents who answered this questions are indicated in figure 4.5 below 


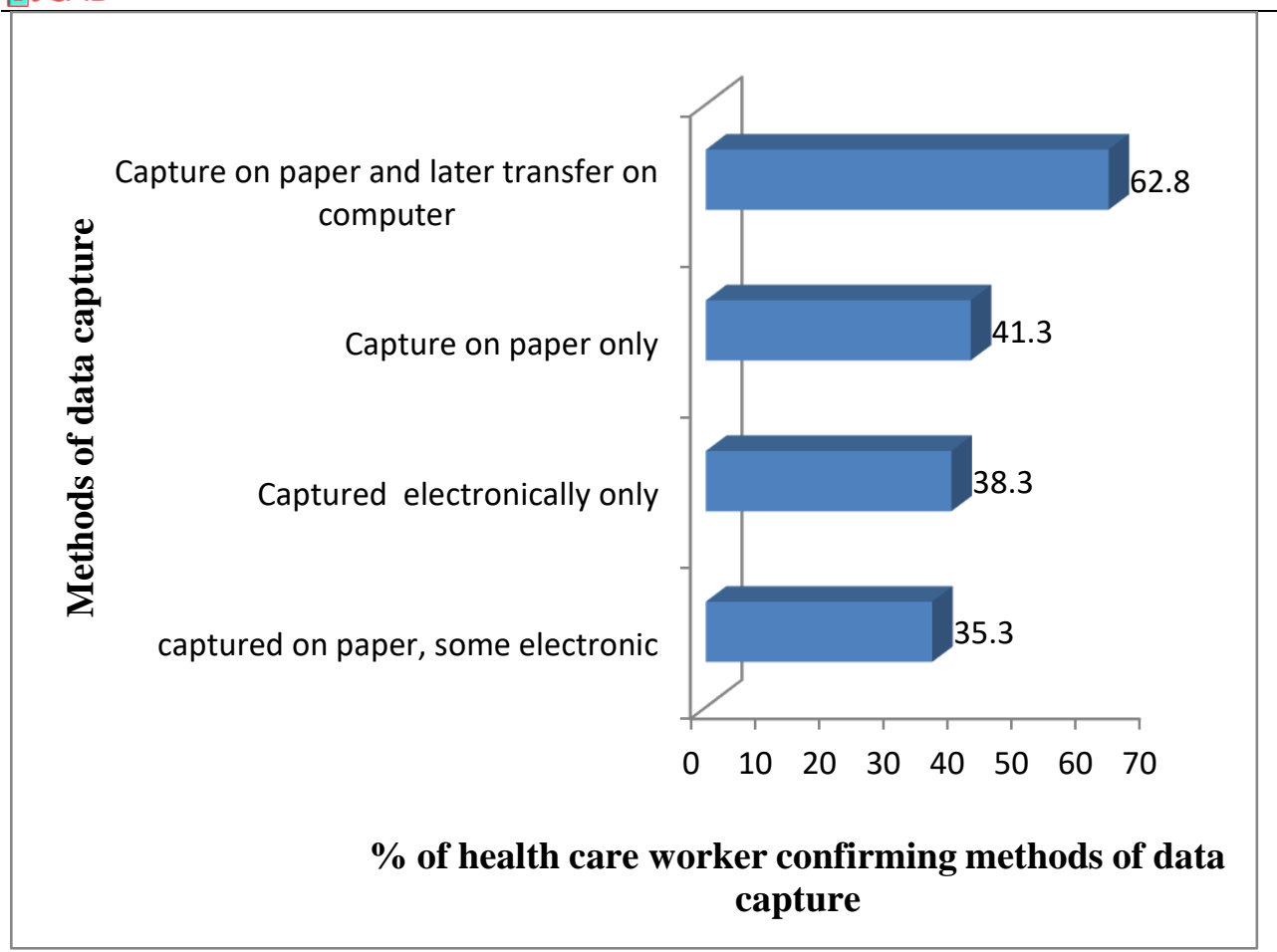

Figure 2 Methods of data capture in the selected hospitals

\section{Source: Research questionnaires 2020}

Figure 2 above revealed that in all the selected hospitals nearly two third $(62.8 \%)$ of respondents confirmed that patient data were captured on paper first and entered later by data personnel to the computer. Below half $(41.3 \%, 38.3 \%, 35.3 \%)$ of the respondents confirmed that patient data were Captured only on paper, patient data were Captured using computerized system at the point of registration, there is parallel Captured of patients' records both on paper and online during patient treatment by the doctor. On overall, The implication of this result is that paper was more prominently being used for patient data capturing in the selected hospitals in the study area than electronic data capturing, which is likely to interfere with clinical workflow and bring confusion as to which document is more authentic because of fragmented document which islabour intensive and waste of time. According to WHO (2006) and Ondieki (2017), use of paper based medical records has increased possibility of medical error, poor communication, duplication of records among other challenges in most hospitals. Considering that majority of the hospitals understudy are paper based, they are likely to face the above challenges.

\subsection{Intended Purpose of using EMR in selected hospitals}

EMR serves a significant role in enhancing service delivery. Henry Schein Medical Systems (2019) identify better diagnosis and treatment; minimize errors in personal records and enhance patient care; aid in the proper decision-making process, among other purpose of using EMR in hospitals. To confirm the operational health workers level of understanding of benefits EMR implementation, 269 operational health workers were asked to confirm the various purpose of using EMR which ranges from registration of patient, support treatment improve patient's services among others in terms of "Yes or No". The result is presented in figure 3. 


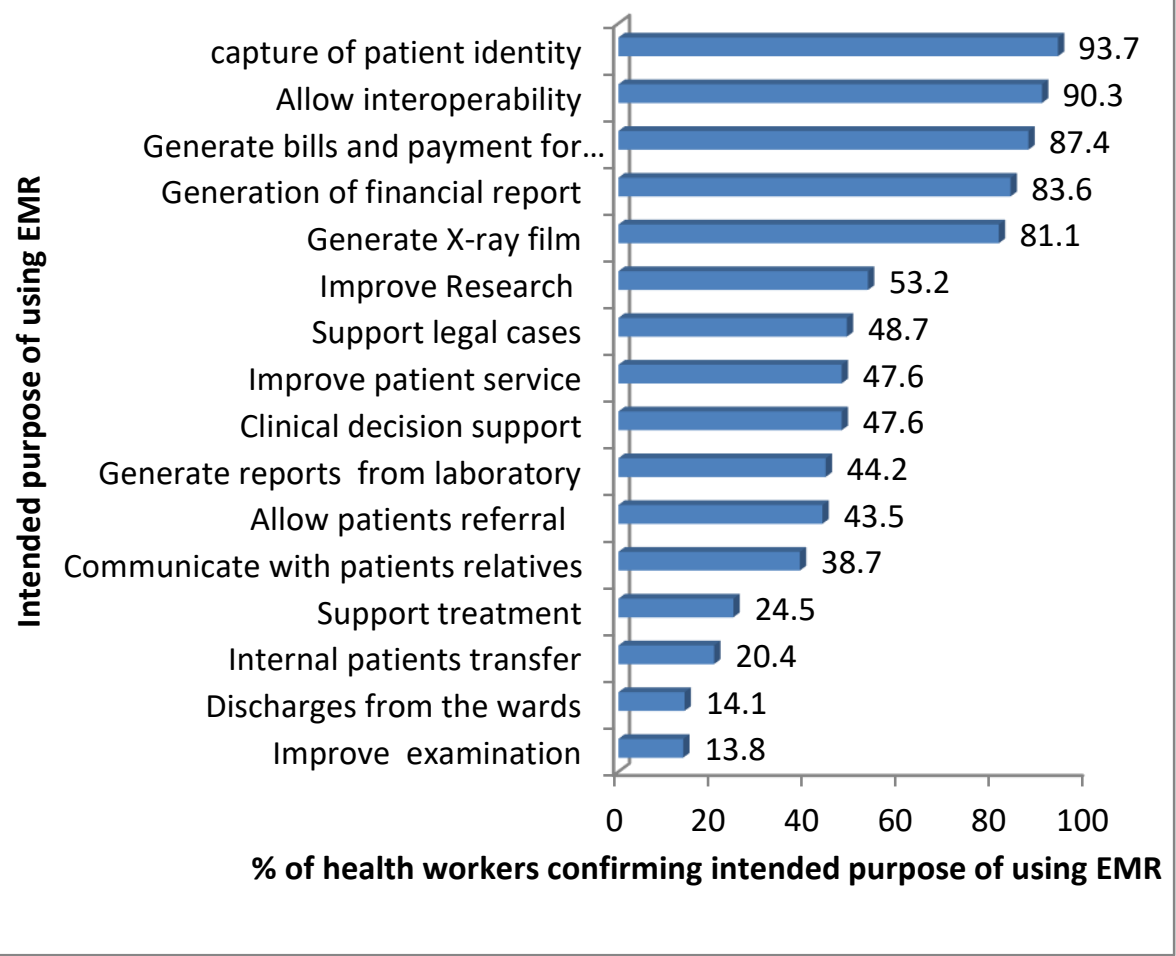

Figure 3 intended Purpose of using EMR

\section{Source: Research questionnaires 2020}

From the responses of the health care staff in the selected hospitals as shown in figure 4.7, majority $(81.1 \%-93.7 \%)$ confirmed that the intended purpose of using EMR is to improve and generate X-ray film translation, generation of financial report for the purpose of planning and decision making, generate bills and payment for treatment and other essential services, Allow interoperability between the doctors and pharmacy for drug prescription, improve capture of patient identity. About Half $(53.2 \%)$ of the respondents confirmed that is it intended to improve research. On the contrary, less than half $(13.8 \%-48.7 \%)$ of the respondents could not agreed that the intended purpose of using EMR is to improve Patient examination by healthcare units, approve Discharges of patience from the wards, document patient referral from one unit of the hospital to another, support treatment through Doctors Notes, improve Communication with patients relatives, allow patients referral from one hospital to another, generate reports through Ordering of investigations from the laboratory, improve clinical decision support, improve patient service through Nursing notes, support legal cases. The researcher deduced from the results that the understanding of the hospital understudy on benefits that could be derived from implementing EMR is only in few treatment areas which are to improve treatment of patients, allow interoperability between the doctors and pharmacy for drug prescription and generate bills and payment for treatment, generate $\mathrm{x}$-ray report and for research purpose. the response on other benefits operational health workers can derive in other major treatment areas like document patient referral from one unit of the hospital to another, support treatment through Doctors Notes, improve Communication with patients relatives, allow patients referral from one hospital to another, generate reports through Ordering of investigations from the laboratory, improve clinical decision support, improve patient service through Nursing notes, support legal cases was not understood which can result to low readiness of EMR implementation. 
According to the universally accepted purpose for using medical records as stated by Manca (2015), medical records are expected to support treatment, improve communication, improve clinical support improve patients examination, reduce patient waiting time among others, the low understanding of purpose of EMR in treatment areas means that the hospitals under study are not fully ready for EMR implementation which is likely to led to poor service delivery, increase patients waiting time, poor clinical decisions and communication among others, which may be as a result of poor readiness factor.

The conclusion on existing medical records is that hospitals under study basically use paper based medical records with some level of hybrid penetrations in billing and patients registration modules. The finding also conclude that health worker intention of using EMR is to Capture of patient identity, Allow interoperability, Generate bills and payment for treatment, Generation of financial report, Generate X-ray film, Improve Research.

\subsection{EMR Implementation plans coverage in selected hospitals.}

Implementation plan coverage is a strategy towards the successful adoption of electronic medical records. A good implementation plan coverage should contain an assessment of readiness for EMR implementation, recruitment of implementation committee, implementation cost analysis, Migration of patient data to electronic format plan, training program for operational health works, evaluation strategies, appraisal of existing problems among others.

To confirm the areas covered by the existing plans for the implementation of EMR in the selected hospitals, twenty (20) strategic managers were asked to respond to questions in terms of "Yes or No" in relation to strategic mangers EMR implementation plans available in the Hospitals understudy. figure 4.9 below shows the analysis from the respondents.

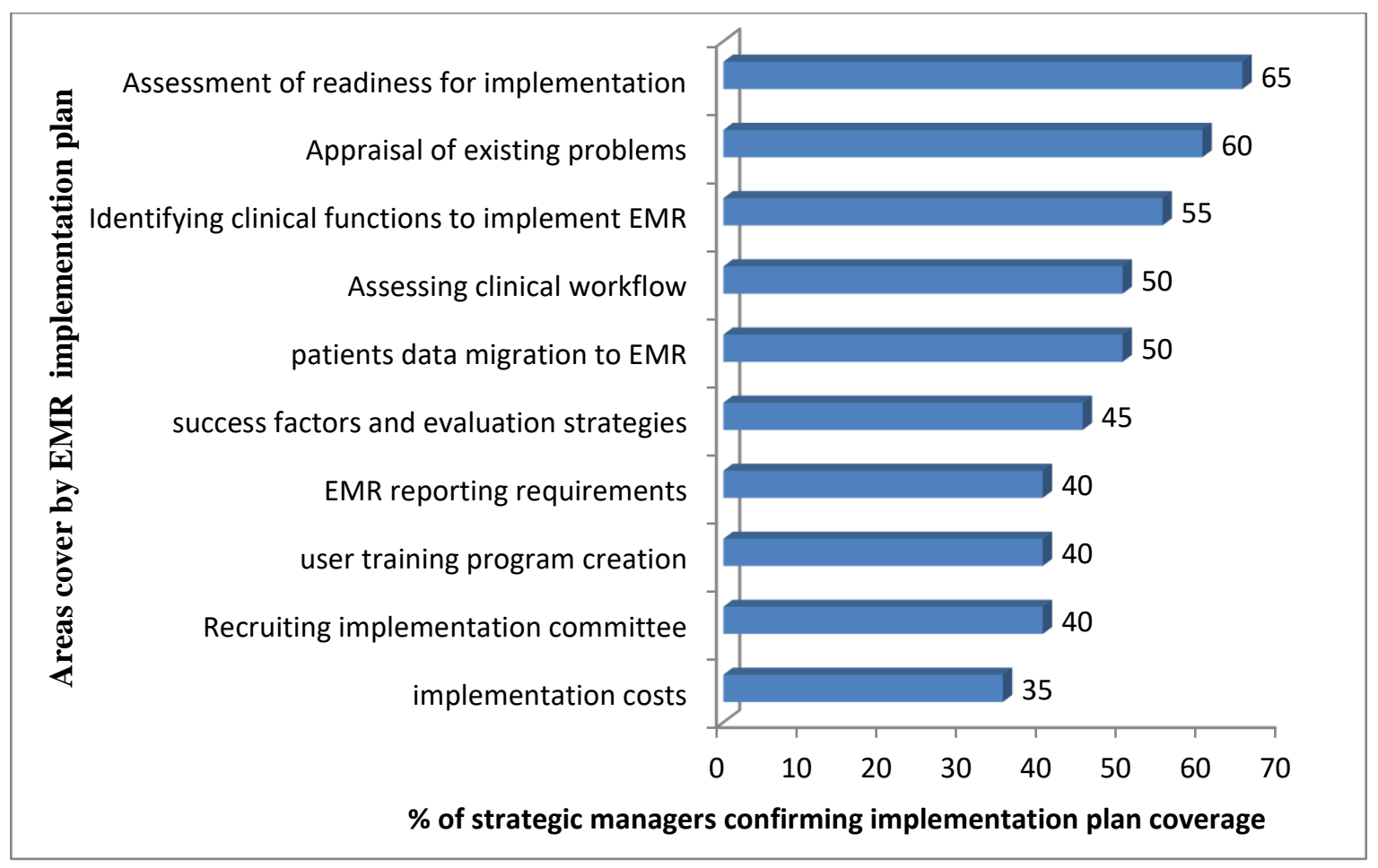

Figure 4 EMR implementation plan coverage

\section{Source: Research questionnaires 2020}


Figure 4 above shows that the EMR implementation plan cover was grossly low. Above half (50-65\%) of the respondents also confirmed that Assessment of readiness for implementation, Appraisal of existing problems and data- flow, and Identifying area of clinical functions to implement EMR were high. out of the 20 respondents, less than half (40\%) of the respondents confirmed that Recruiting implementation committee, Create a user training program Identifying EMR reporting requirements, Outlining expected implementation costs, Define critical success factors and evaluation strategies, Identifying EMR reporting requirements was not cover in the implementation plan. The import of this is that the strategic managers implementation plan coverage did not cover Recruiting implementation committee, Create a user training program Identifying EMR reporting requirements, Outlining expected implementation costs, Define critical success factors and evaluation strategies, Identifying EMR reporting requirements in the selected hospitals. The implication of this is that the study area are not fully prepared for the implementation of EMR in there hospitals. Rouse (2012) report that hospitals with poor implementation plan coverage are likely to face problems associated with poor staff performance, poor implementation process, poor funding among others. The hospitals understudy is likely to face such challenges as a result of poor planning and her inability to create implementation committee outline cost and inability to develop a training program for staff members.

\subsection{Challenges of paper based Medical Records in hospital}

Hospitals are faced with challenges of management of medical records, some of the challenges resulted from "poor Medical Records Management standards, preservation, and conservation policies, inadequate storage facility, and poor filing system; inadequate funding among others. The purpose of this study is to identify the challenges of paper based medical records in southwest Nigeria. To confirm challenges of paper based in the selected hospitals, the three hundred and ninety seven (397) health workers respondents were asked question with regards to challenges of paper based in Selected Hospitals, two hundred sixty nine (269) responded. The result is indicated in figure 6 below. 


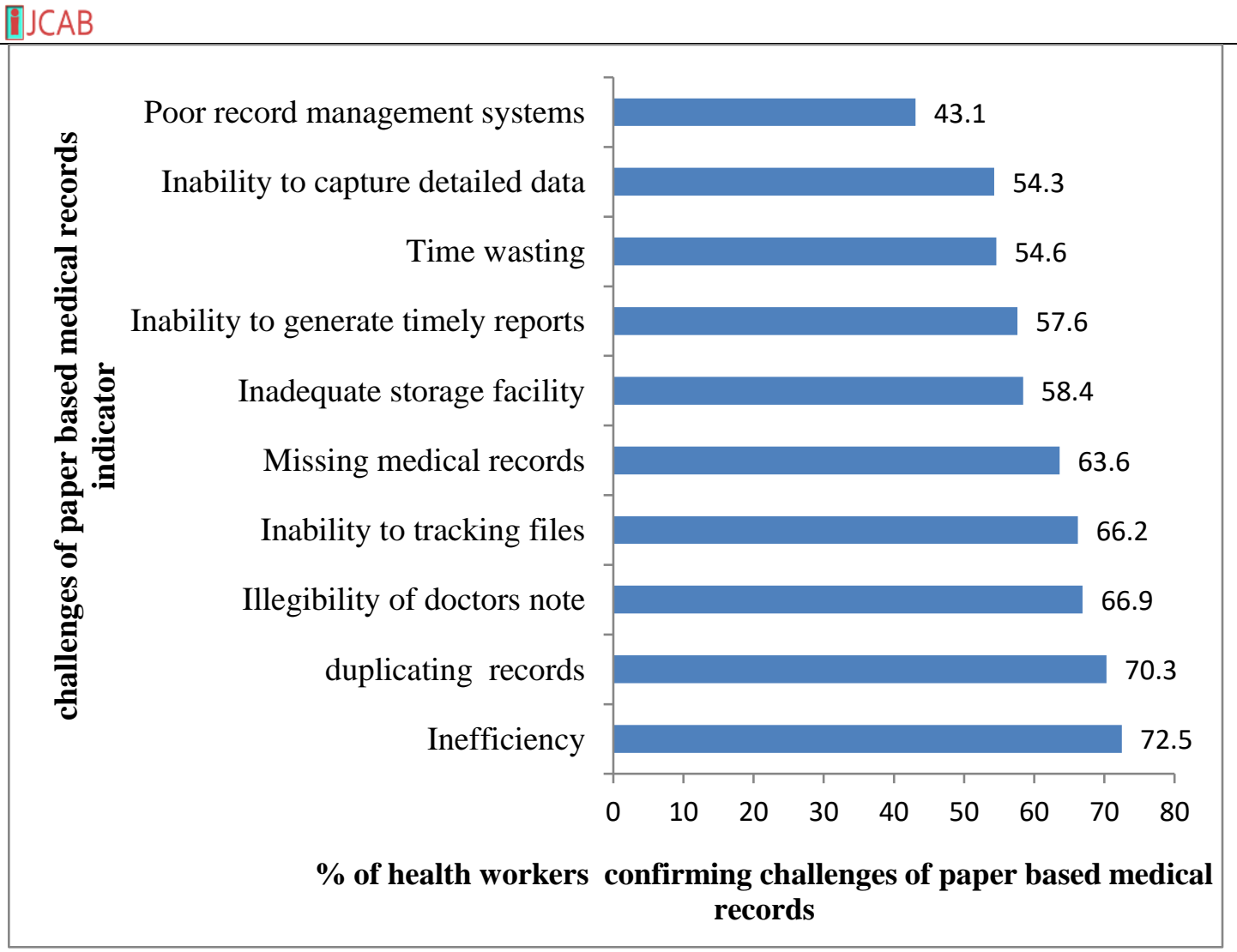

Figure 5 challenges of paper based medical records system in the selected hospitals

\section{Source: Research questionnaires 2020}

Results presented in figure 5 on the challenges experienced by medical staff in using paperbased medical records in the selected hospitals in Southwest Nigeria, almost three quarter (70.3-72.5\%) confirmed that the hospitals face the challenge of duplicating records, and inefficiency. Another (63.6-66.9\%) identify missing medical records, inability to tracking files, and illegibility of doctors' note. Similarly, more than half (54.3-58.4\%) of the respondents also confirmed inability to capture detailed data, time wasting, inability to generate timely reports and inadequate storage facility as a major challenge of paper passed medical records. Below half $(43.1 \%)$ of the respondents affirmed poor records management systems. This means that the challenges of paper based medical records experienced by heath care workers in the selected teaching hospitals were inefficiency, missing records, illegibility of doctors' notes among others. The report of Ondieki (2017) shows that paper based medical records system are faced with challenges like rendering timely and effective health services delivery to citizens due to poor management of patients records system in the hospital, which usually leads to long patient waiting times and medical error experienced in the area of drug prescription and doctors note. Hospitals understudy are likely to face with this challenges as listed above.

\subsection{Challenges of Using EMR in selected hospitals}

Despite the significant role of EMR to enhance service delivery in the health sector in countries where it has been implemented some challenges still abound. To confirm Challenges of Using EMRin the selected hospitals, the three hundred and ninety seven (397) health workers respondents were asked question with regards to Challenges of Using EMRin Selected Hospitals, two hundred sixty nine (269) responded. The result is indicated in figure 7 below. 


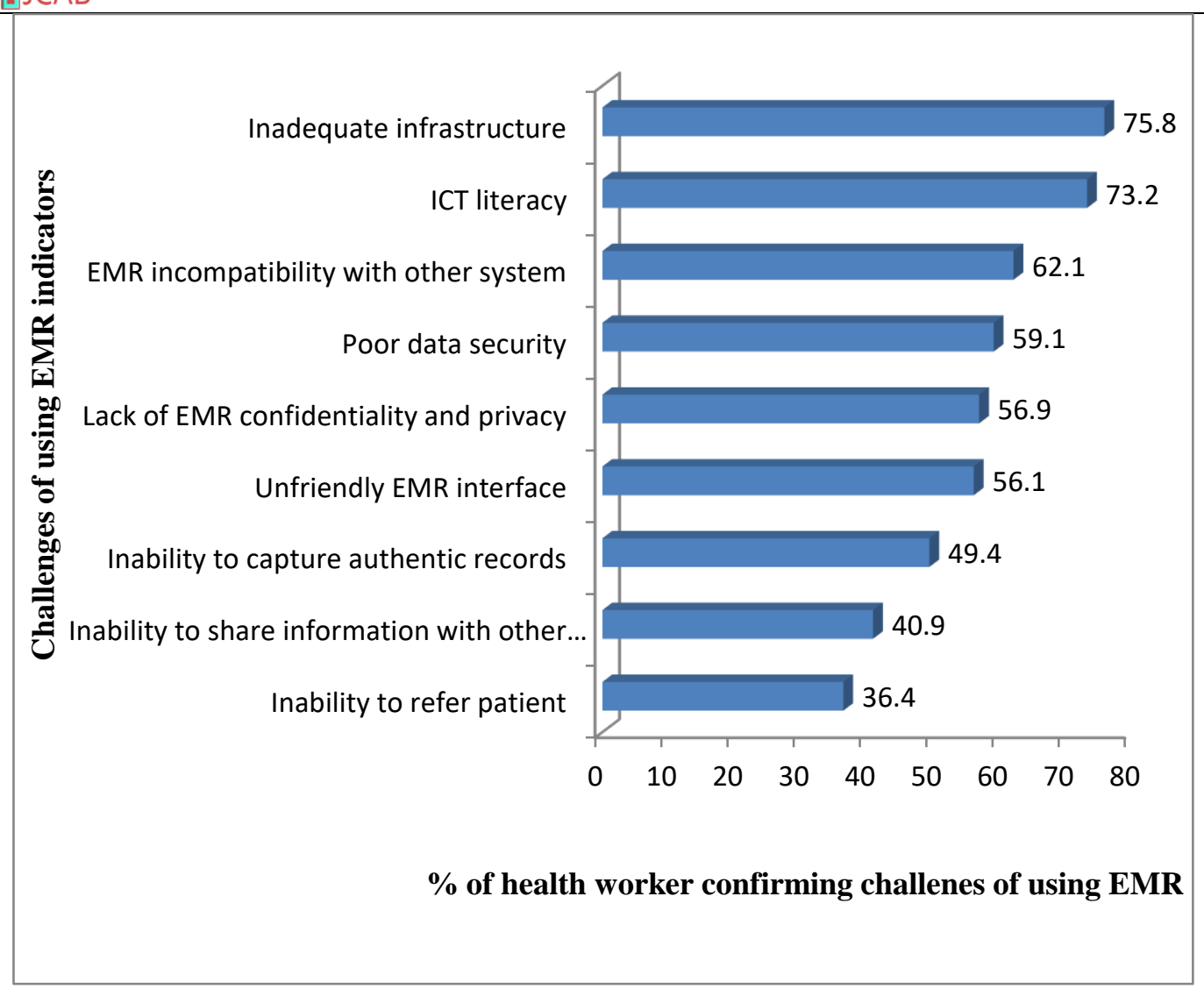

Figure 6 challenges of using EMR in the selected hospitals

\section{Source: Research questionnaires 2020}

The researcher found out in figure 6 that inadequate infrastructure, ICT literacy, was identified by three quarter $(73.2,75.8 \%)$ of the respondents as the greatest challenge of using EMR in the hospitals. Nearly two third (62.1\%) confirmed EMR incompatibility with other systems as one of the prominent challenges of using EMR in the hospitals. Over half (56.1-59.1\%) of the respondents confirmed that poor data security, Lack of EMR confidentiality and privacy and Unfriendly EMR Interface are challenges of using EMR implementation. the import of this study is that there are a lot of challenges facing the full implementation of EMR in the selected hospitals.

\subsection{Challenges of EMR Implementation the Hospitals}

To confirm Challenges of Using EMRin the selected hospitals, the twenty (20) strategic managers were asked question with regards to Challenges of implementing EMRin the Selected Hospitals. The result is indicated in figure 7 below. 


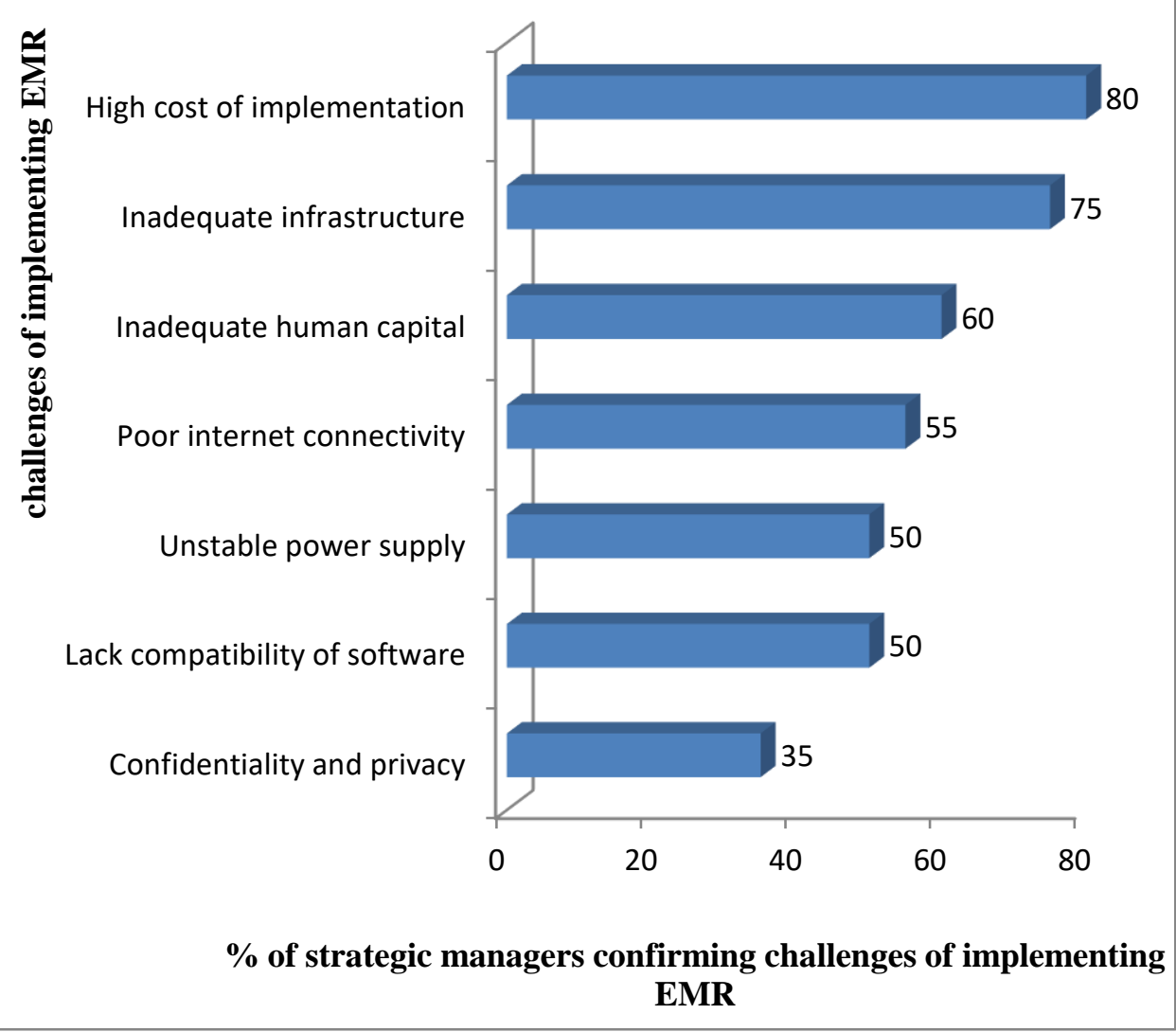

Figure 7 challenges of implementing EMR in the selected hospitals

\section{Source: Research questionnaires 2020}

From the data in the figure, majority $(75 \%, 80 \%)$ of the respondents confirmed cost of implementing full function of EMR and inadequate infrastructure as the greatest challenge by the strategic healthcare managers to implement EMR. while nearly two thirds $(60 \%)$ of the respondents confirmed inadequate human capital as a challenge for implementation of EMR. half and above $(50 \%, 55 \%)$ of the respondents affirmed that unstable power supply, compatibility software and poor internet connectivity is a great challenge to implementation of EMR. The import of this is that cost of implementing full EMR function, inadequate infrastructure; inadequate human capital and poor internet connectivity are the major challenges hampering the readiness and implementation of full EMR functions in the selected hospitals. Attah (2017) reported that weak national e-Health strategy and policy, poor power supply, poor government commitment to policy creation, funding and legislation, inadequate ICT infrastructure and poor internet connectivity, poor remuneration of health care workers, shortage of healthcare personnel among others has lead to the various challenges experienced in the implementation of EMR in hospitals. The hospitals understudy are likely to face the above listed problems as a result of the divert challenges identified by Attah (2017).

\section{Conclusion and Recommendations}

\subsection{Conclusion}

This study sought to assess the implementation of Electronic medical records for service delivery in selected state hospitals in southwest Nigeria. Revelations from the research have showed most medical records practices are still in a paper-based format. The entire hospitals' understudy has implemented one form of EMR or the other. It is also concluded that health workers only identify data capture of patient identity, interoperability between the doctors and 
pharmacy for drug prescription, generate X-ray film translation among others as the intended purpose of implementing EMR, without considering other key benefits of EMR such as to improve Patient examination by healthcare units, approve discharges of patience from the wards, document patient referral from one unit of the hospital to another, support treatment through doctors notes, improve communication with patients relatives, allow patients referral from one hospital to another, generate reports through Ordering of investigations from the laboratory, improve clinical decision support among others.

The study conclusively identified significant challenges of EMR implementation in state teaching hospitals in southwest Nigeria. The challenges are separated into three stages, challenges of paper-based (repeated records, the illegibility of doctor's note, and inability/difficulty in tracking files, missing medical records, among other challenges), challenges of using EMR in selected hospitals as (inadequate infrastructure, ICT literacy, EMR incompatibility with other systems, insufficient data security, EMR confidentiality and privacy, and unfriendly EMR Interface), and finally, challenges of EMR implementation in the selected hospitals strategic manager's (the cost of implementing the full function of EMR was the most significant challenge identified by the strategic healthcare managers, other challenges are inadequate infrastructure and inadequate capital). This study has shown challenges hindering the readiness and full implementation of EMR in state hospitals in Southwest Nigeria.

\subsection{Recommendation}

Based on the study's findings, the following recommendations were deemed to be appropriate To deal with problems associated with paper-based medical records and considering the lack of funds in the studied hospitals, the study recommends that strategic managers in the hospitals under study should implement the EMR in phases to allow graduate inclusion of EMR system in selected treatment area of the hospital to enable the hospitals to benefit from the intended purposes of implementing electronic medical records in treatment areas such as improve Communication with patients relatives, improve clinical decision support, support legal cases among others, to improve service delivery. It was noted that hospitals lacked adequate funding, political good will, implementation plans, staff readiness, and availability of EMR standards and ICT policy, which has affected patient treatment and follow up negatively. To deal with the problem, the study recommends that strategic managers should have a financial plans and budgeting system that will help to implement EMR in phases, including staff training programs, set up implementation planning and committees, and evaluation strategies to improve on her EMR process in southwest hospitals in Nigeria.

\section{REFERENCES}

Acquah-Swanzy, M (2015). Evaluating Electronic Health Record Systems in Ghana: The case of EffiaNkwanta Regional Hospital.(Master's Thesis, The Arctic University of Norway). Retrieved from https://munin.uit.no/bitstream/handle/10037/8080/thesis.pdf?sequence $=2$

Adjorlolo, S., \&Ellingsen, G. (2013). Readiness Assessment for Implementation of Electronic Patient Record in Ghana: A Case of the University of Ghana Hospital. Journal of Health Informatics in Developing Countries 7(2), 128-140.

Al Alawi, S ., Al Dhaheri, A., Al Baloushi, D. Al -Dhaheri, M \&Prinsloo, E.A (2014) Physician User Satisfaction With an Electronic Medical Records System in Primary Healthcare Centres in Al Ain: a qualitative study. Retrieved from https://bmjopen.bmj.com/content/4/11/e005569

Aldosari, B., Al-Mansour, S., Aldosari, H. \&Alanazi, A. (2018).Assessment of factors influencing nurses acceptance of electronic medical record in a Saudi Arabia hospital. Informatics in Medicine, 10, 82-88. 
[IJCAB

Ayangbekun O. J, \&Oke A.E (2014) Comparative Analysis of Existing Health Information Systems for the Development of Nigerian Health Sector.International Journal of Innovative Research in Computer and Communication Engineering. 2(7),4981-4989. Retrieved from www.ijircce.com

Ayanlade, O.S (2018) Electronic Medical Record System as a central ICT tool for quality healthcare services: Nigeria as a case study. Journal African Journal of Science, Technology, Innovation and Development.10(2),147-157. Retrieved from https://doi.org/10.1080/20421338.2017.1412609

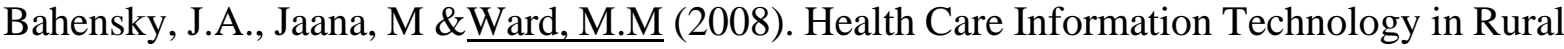
America: Electronic Medical Record Adoption Status in Meeting the National Agenda. Journal of rural health.24(2).retrieved from https://onlinelibrary.wiley.com/doi/10.1111/j.1748-0361.2008.00145.x

Baldwin, H (2019). The Electronic Medical Records Features You Need. Retrieved from https://www.allbusiness.com/the-electronic-medical-records-features-you-need10206838-1.html

Bali, Bali, Iyer and Iyer (2011) Management of Medical Records: Facts and Figures for Surgeons. Journal of Maxillofacial \& Oral Surgery. 10(3): 199-202. Retrieved from doi: $10.1007 / \mathrm{s} 12663-011-0219-8$

Beebeejauna, M.R, Chittoo, H (2017). An Assessment of e-Health Readiness in the Public Health Sector of Mauritius. International Journal of Sciences: Basic and Applied Research.Retrieved http://gssrr.org/index.php?journal=JournalOfBasicAndApplied

from

Beeson, K (2017 may 13th). EHR Implementation Plan: Your 8-Step Checklist (blog post).

Retrieved fromhttps://www.ehrinpractice.com/ehr-implementation-plan.html

Begoyan, A (2007), An Overview of Interoperability Standards for Electronic Health Records. Integrated Design and Process Technology.Integrated Design and Process Technology.1-8. Retrieved from https://pdfs.semanticscholar.org/5ca5/32439868b9fac13bf5a0d6b46365280828d3.pd $\underline{\mathrm{f}}$

Chang, F. and Gupta, N (2015). Progress in electronic medical record adoption in Canada.Canadian Family Physician. 61(12), 1078-1084. Retrieved from https://www.ncbi.nlm.nih.gov/pmc/articles/PMC4677946/

Creswell, J W (2009), Research Design: Qualitative, Quantitative, and Mixed Methods Approaches. SAGE Publications, Inc. India.pp 45

De Vaus, D. A. (2001) Research Design in Social Research. London: SAGE pp54

Dhar, P (July $3^{\text {rd }}, 2018$ ) why EHRs are embracing comprehensive health records. (blog post). Retrieved from https://www.elationhealth.com/care-gaps-blog/chr/

Flores, L.E (2015)Paper Based Medical Records. (Blog post).Retrieved from http://www.zillioncorporation.com/index.php/en/paper-based-medical-records-en

Floyd, B. (2013). Four Ways to Improve Support Service Delivery in Acute Care Hospitals. Becker's hospital reviews. Retrieved fromhttps://www.beckershospitalreview.com/hospital-management-administration/4ways-to-improve-support-service-delivery-in-acute-care-hospitals.html

Fraser, H.S.F, Biondich, P. Moodley, D. Choi, S. Mamlin, B.W. Szolovits, P (2005). Implementing electronic medical record systems in developing countries. The Journal of Innovation in Health Informatics 13(2), 83-95. Retrieved from https://www.researchgate.net/publication/7752594

Frey, B.B (2018) Response rate: In The SAGE Encyclopedia of Educational Research, Measurement, and Evaluation. Retrieved from https://dx.doi.org/10.4135/9781506326139.n592 
Ghani, M.K.A, Naguib, R. \& Marshall, I.M (2008) Electronic health records approaches and challenges: a comparison between Malaysia and four East Asian countries. International Journal of Electronic Healthcare.4(1), 78-104. Retrieved from http://www.inderscience.com/offer.php?id=18922

Ghazisaeidi, M, Ahmadi,M, Sadoughi, F \&Safdari, R (2014). An Assessment of Readiness for Pre-Implementation of Electronic Health Record in Iran: a Practical Approach to Implementation in general and Teaching Hospitals.ActamedicaIranica 52(7), 532-544. Retrieved

from https://www.researchgate.net/publication/264903970_An_Assessment_of_Readiness for_PreImplementation_of_Electronic_Health_Record_in_Iran_a_Practical_Approach to_Implementationin_general_and_Teaching_Hospitals

Graham,T.A., Ballermann, M., Lang ,E. , Bullard, M. , Parsons, D. , Mercuur, L., San Augustin, P.\& Ali, S. (2016). Electronic health record perceptions and utilization by physicians in urban emergency departments.Canadian Journal of Emergency Medicine.18(1), 95.Retrieved fromhttps://doi.org/10.1017/cem.2016.226

Halamka, J (2010). Electronic Health Record Standards.Health affairs. Retrieved from https://www.healthaffairs.org/do/10.1377/hpb20100928.658660/full/

Hayes, A (March $3^{\text {rd }}$ 2020).Stratified Random Sampling(blog post). Retrieved from https://www.investopedia.com/terms/stratified_random_sampling.asp

Hossain M.A, Quaresma R, Hasan, M.R and Imtiaz.H (2019).An insight into the bilateral readiness towards telemedicine. Retrieved from https://doi.org/10.1007/s12553-019$\underline{00328-1}$

Idowu, B. Adagunodo, R \&Adedoyin, R (2006). Information technology infusion model for health sectors in a developing country: Nigeria as a case.Journal of the European Society for Engineering and Medicine. Retrieved from https://www.researchgate.net/publication/7061664

Ijeoma, V.C (n.d). Challenges of professional management of patient's medical records in Nigerian Public Hospitals. from https://www.academia.edu/10508920/Challenges_of_Professional_Management_of Patients_Medical_Records_in_Nigerian_Public_Hospitals

Jensen E (2007). ABCs of EMR Financing.For the records 19(4), 36. Retrieved from https://www.fortherecordmag.com/archives/ftr_02192007p36.shtml

Jindal, S. and Raziuddin, F. (2018). "Electronic medical record use and perceived medical error reduction", International Journal of Quality and Service Sciences. 10(1), 84-95. Retrieved from https://doi.org/10.1108/IJQSS-12-2016-0081

Johnblack K. Kabukye, J.K., Keizer, N and Cornet, R (2020).Assessment of organizational readiness to implement an electronic health record system in a low-resource settings cancer hospital: A cross-sectional survey.PLoS ONE 15(6): Retrieved from https://doi.org/10.1371/journal.pone.0234711

Kaelber,D., Greco, P. and Cebul, R.D (2005). Evaluation of a commercial Electronic Medical Record (EMR) by Primary Care physicians 5 Years after Implementation.Retrieved fromhttps://www.ncbi.nlm.nih.gov/pmc/articles/PMC1560716/

Kalogriopoulos, N.A. Baran, J. Nimunkar, A.J \& Webster, J.G (2009)Electronic Medical Record Systems for Developing Countries: Review.31st Annual International Conference of the IEEE EMBS Minneapolis, Minnesota, USA, September 2-6, 2009

Kang'a S, Puttkammer N, Wanyee S, Kimanga D, Madrano J, Muthee V, et al. (2016) A national standards-based assessment on functionality of electronic medical records systems used in Kenyan public-sector health facilities. Int J Med Inform. 97:68-75 
Krejcie, R.V \& Morgan, D.W (1970). Determining sample size for research activities.Educational and Psychological Measurement. Educational and psychological measurement. 30, 607-610. Retrieved from https://home.kku.ac.th/sompong/guest_speaker/KrejcieandMorgan_article.pdf

Kressly, S (2019). 6 common challenges in EHR implementation. Retrieved from https://www.officepracticum.com/blog/6-common-challenges-in-ehr-implementation

Lougheed, $\mathrm{T}$ (2019). The challenge of implementing a patient-centric EMR.CMAJ.191 (5), 144-145.Retrieved from http://www.cmaj.ca/content/191/5/E144

Mag, H (Agust $9^{\text {th }}$, 2010) Evaluating EMR system. (blog post). Retrieved from hcinnovationgroup.com/home/article/13002940/evaluating-ehr-systems

Mangundjaya, W.L.H (2013). Leadership, Readiness to Change, and Commitment to Change. Proceedings of the 7th International Management Conference "New Management for the New Economy", November 7th-8th, 2013, Bucharest, Romania

Mascot, H (January 25 ${ }^{\text {th }}$, 2017). Nigeria: Why Hospitals Should Embrace Electronic Medical Records (blog post). Retrieved from https://medium.com/curacel/nigeria-whyhospitals-should-embrace-electronic-medical-records-bf5f4fac1298

Odekunle, F.F., Odekunle, R.O \& Shankar, S (2017). Why sub-Saharan Africa lags in electronic health record adoption and possible strategies to increase its adoption in this region. International journal of health sciences.11(4), 59-64.Retrieved from https://www.ncbi.nlm.nih.gov/pmc/articles/PMC5654179/

Ogunsipe A. (2019). Healthcare on Demand: 15 Startups Reinventing Healthcare Delivery in Africa. Retrieved from https://acefied.com/2019/01/02/healthcare-on-demand-15startups-reinventing-healthcare-delivery-in-africa/

Olaronke ,I. Ishaya ,G. Rhoda, I \& Janet, O (2013) Interoperability in Nigeria Healthcare System: The Ways Forward. International Journal of Information Engineering and Electronic Business.4, 16-2. Retrieved from http://www.mecs-press.org/

Oluwaseun, O \&Olaronke. I (2015) Strategies for Managing Information Flow in Nigeria Healthcare System. International Journal of Applied Information Systems (IJAIS).9(8), 15-21. Retrieved from 10.5120/ijais2015451443

Ondieki, F (2017). Effects of Health Records Management on Service Delivery: A Case Study of Kisii Teaching and Referral Hospital. Journal of Hospitality Medical Management.3(1). Retrieved from http://hospital-medicalmanagement.imedpub.com/effects-of-health-records-managementon-servicedelivery-a-case-study-of-kisiiteaching-and-referral-hosp.php?aid=19550

Onigbogi O.O, Poluyi A.O, Poluyi C.O, \&Onigbogi, M.O (2018).Doctors' Attitude and Willingness to Use Electronic Medical Records at the Lagos University Teaching Hospital, Lagos, Nigeria.Online Journal of Public Health Informatics.10 (2).Retrievedfromdoi: 10.5210/ojphi.v10i2.8416

Randall,C.L.Hort, K . $\underline{\text { Huebner, }}$ C. E, Mallott,E, Mancl,L, Milgrom, P. Nelson, L, Senturia, K. Weiner, B.J, Cunha-Cruz, J. (2020) Organizational Readiness to Implement System Changes in an Alaskan Tribal Dental Care Organization. JDR clinical and translational research 5(2):156-165. Retrieved in doi: $10.1177 / 2380084419871904$.

Rouse, M (February $\left.7^{\text {th }}, 2012\right)$, EHR implementation plan (blog post). Retrieved from https://searchhealthit.techtarget.com/definition/EHR-implementation-plan 
Rutten, L.J.F., Vieux, S.N. St Sauver, J. L., Arora,N.K., Moser,R.P., Beckjord,E.B., \&Hesse, B.W (2014). Patient perceptions of electronic medical records use and ratings of care quality. Patient Related Outcome Measures.5, 17-23. Retrieved from https://www.ncbi.nlm.nih.gov/pmc/articles/PMC3968078/

Salah, A \&Alsadi, M (2019). Electronic Health Records Implementation Readiness: An Integrative Review. Open journal of Nursing. 9 (11). Retrieved from http://www.scirp.org/journal/ojn

Sarkies MN, Bowles K-A, Skinner EH, Mitchell D, Haas R, Ho M, Salter K, May K, Markham D, O'Brien L, Plumb S, Haines T.P.(2005), Data collection methods in health services research - hospital length of stay and discharge destination. Applied Clinical Informatics 6: 96-109.http://dx.doi.org/10.4338/ACI-2014-10-RA-0097

Schulman J (2006) Managing your patients' data in the neonatal and pediatric ICU. An introduction to databasesand statistical analysis.Blackwell Publishing; Oxford.Pp 9-12

Shetler, P (October 29 $\left.{ }^{\text {th }}, 2018\right)$. Australia Struggles with Rollout of National Electronic Health Record System (blog post). Retrieved from https://www.darkdaily.com/australiastruggles-with-rollout-of-national-electronic-health-record-system/

Stephanie (2014).Cronbach's Alpha: Simple Definition, Use and Interpretation. Retrieved from https://www.statisticshowto.datasciencecentral.com/cronbachs-alpha-spss/

Strata (2018, December 1). Why Strategic Planning is Important in Healthcare (blog post).

Retrieved from https://www.stratadecision.com/blog/why-strategic-planning-isimportant-in-healthcare/

Swathi, D (July 18 ${ }^{\text {th }}, 2018$ ). Which country is the leader for electronic health record system? (blog post). Retrieved from www.quora.com/which-country-is-the-leader-for-ehealth-record-systems

Tanner, K (2018). Research Methods: Information, Systems, and Contexts ( $2^{\text {nd }}$ edition). [ebook]. Retrieved from http://dx.doi.org/10.1016/B978-0-08-102220-7.00014-5

TechTarget (2010) Hybrid Health Records (HHR) (blog). Retrieved from https://searchhealthit.techtarget.com/definition/hybrid-health-record-HHR

Thompson A, Castle E, Lubeck P, \&Makarfi P S. (2010). Experience implementing OpenMRS to support maternal and reproductive health in Northern Nigeria.Study Health Technology Information. 160(1):332-336. Retrieved from https://www.ncbi.nlm.nih.gov/pubmed/20841703

Tubaishat, A. (2018). Perceived usefulness and perceived ease of use of electronic health records among nurses: application of technology acceptance model. Informatics for Health and Social Care, 42(4) 379-389.

Wacker, C (2021) The Reality of Finding Meaning in Meaningful Use - How a Hybrid EMR System Can Help YourPractice Cut Costs and Increase Efficiency. Spring city.Great Valley Publishing Company

Waithera, L., Muhia, J \&Songole, R (2017). Impact of Electronic Medical Records on Healthcare Delivery in Kisii Teaching and Referral Hospital. iMedPub Journals. 3(4), 21. Retrieved from DOI: $10.21767 / 2471-299 X .1000062$

Wamae P (2015) Implementation of Electronic Medical Records in Kenyan Public Hospitals: Challenges and Opportunities. (Doctoral Dissertation, Kenyatta University Nairobi Kenya). Retrieved from https://ir-library.ku.ac.ke/handle/123456789/15091

Weiner, B.J (2009), A theory of organizational readiness for change.Implementation $\begin{array}{llll}\text { Science.4 (67). } & \text { Retrieved }\end{array}$ http://www.implementationscience.com/content/4/1/67

Weiner, B.J., Amick H., Lee, S.D (2008) Review: Conceptualization and Measurement of Organizational Readiness for Change: A Review of the Literature in Health Services 
Research and Other Fields. Medical care research and review.65(4):379-436. Retrieved in doi: $10.1177 / 1077558708317802$.

Yusif, S. Hafeez-Baig, A \& Soar J (2017). E-Health readiness assessment and measuring tools: A systematic review.International Journal of Medical Information. 107, 56-64. Retrieved from doi: 10.1016/j.ijmedinf.2017.08.006.

This is an open-access article published and distributed under the terms and conditions

of the (c) Creative Commons Attribution 4.0 International License of United States unless otherwise stated. Access, citation and distribution of this article is allowed with full recognition of the authors and the source. Authors seeking to publish with an Internationally Peer Reviewed Journals should consider https://www.ijcab.org/ by writing to the Editor at editor@ijicab.org or submitting online at https://journals.ijcab.org/journals/index.php. The articles must be quality and meet originality test.

$\frac{\text { IJCAB }}{\text { Publishing Group }}$ 